Article

\title{
The Attractiveness of Adaptive Heritage Reuse: A Theoretical Framework
}

\author{
Hung-Ming Tu( \\ Department of Horticulture, National Chung Hsing University, Taichung 40227, Taiwan; \\ hmtu@dragon.nchu.edu.tw
}

Received: 29 February 2020; Accepted: 15 March 2020; Published: 18 March 2020

check for

updates

\begin{abstract}
Adaptive heritage reuse is a useful method to bring new meaning into a culture, manage heritage sites, and promote tourism development. However, it is not always successful, and there is no theoretical framework to understand its attractiveness and value. This study aimed at developing such a theoretical framework based on the analysis of nine cases of adaptive heritage reuse in Taiwan. The probe question technique of qualitative interview was used to assess the attraction framework. A total of 90 respondents were interviewed based on constant comparative analysis with the sampling strategy of theoretical saturation. The results illustrate the heritage and activities of the reuse environments, including natural and regional environments. These environments produce recreational values, including self-growth, health benefits, and social benefits. As promoting activities is an important attraction for tourists in the heritage reuse environment, the natural environment can be used to plan and design heritage outdoor activities. Finally, the regional environment can be an important basis for assessing the feasibility of adaptive heritage reuse, including historical streets, surrounding tourist attractions, and high transportation accessibility. This theoretical framework can be used to achieve sustainable management of heritage sites.
\end{abstract}

Keywords: adaptive heritage reuse; natural environment; regional environment; recreational values; health benefit

\section{Introduction}

Heritage is a critical element of cultural development, and cultural heritage is an irreplaceable source of life and inspiration [1]. The UNESCO World Heritage Centre encourages countries across the globe to protect their cultural heritage and establish management plans to conserve heritage sites [1]. Adaptive reuse entails converting buildings sustainably by modifying their function based on the requirements of new or existing users [2]. As such, adaptive heritage reuse is an important strategy for the preservation of heritage architecture [3], and the process of adaptive heritage reuse transforms heritage buildings into usable locations, providing the additional benefit of achieving sustainable regeneration [4]. Adaptive heritage reuse is a widespread method to preserve the value of heritage, including industrial, religious, public, residential, military, and commercial heritage sites [5]; attract private funds; and reduce the financial burden on governments [6,7].

Although adaptive heritage reuse includes multiple fields and functions [5], leisure and tourism are the primary reasons to preserve the value of heritage sites and attract funds. Likewise, heritage has become an important component in the development of leisure and tourism [8,9]. Traditional rural tourism buildings are important reuse buildings. The research by Leanza et al. [10] and Porto et al. [11], for example, contributed to create awareness in the local communities about the need of protecting traditional rural buildings for heritage protection and tourism purposes. Adaptive heritage reuse also plays an important role in urban sustainable development and regeneration, providing economic, cultural, and social benefits $[4,12,13]$. The reuse process is one of the most sustainable forms of urban 
development as it avoids demolition and reconstruction and combines environmental benefits, energy savings, carbon emission reduction, and social and economic benefits [14]. Therefore, the adaptive reuse of historical buildings has become a popular method to reinvigorate culture, manage heritage, and develop tourism.

The attractiveness or appeal of a travel destination, which determines in part how visitors determine where they will travel, consists of several multidimensional attributes, including anticipating and satisfying the demands and expectations of visitors at the site through various facilities and services [15]. Promoting a heritage destination to visitors is an important economic strategy for the sustainable management of adaptive heritage reuse, which is not always successful $[3,16]$. In Cairo, for example, several adaptive heritage reuse projects have failed to achieve the expected benefits of adaptive reuse and have produced symptoms of deterioration because of unsystematic and unscientific reuse processes [3]. In its 400-year history, Taiwan has passed through several historical stages and has been controlled by the Netherlands; Spain; the Ming and Qing dynasties; Japan; and, currently, the Republic of China. Taiwan's ancient settlements gradually expanded and evolved over 400 years into modern urban areas, and Taiwan's government has selected some of these older sites for preservation as heritage sites [17]. Taiwan's government has also often reused heritage sites for tourism purposes. In Taiwan, several adaptive heritage reuse projects do not attract visitors; thus, they do not generate income, as they fail to maintain the minimal needs of management and self-sufficiency. Some examples of struggling adaptive heritage reuse projects include the Taichung Broadcasting Bureau and the Taichung Mayor's House. From the perspective of economic efficiency, and when the non-economic value is not considered, preserving urban heritage is an expensive investment, and the initial renovation and high maintenance costs place enormous burdens on management [14]. Therefore, understanding a heritage destination's attractiveness will improve economic efficiency and promote sustainable management.

Preserving heritage architecture, as well as other elements, is an important aspect of promoting a destination's attractiveness, and the process of adaptive heritage reuse contributes to a destination's attractiveness by providing recreational benefits for visitors. From the perspective of leisure and recreation, the adaptive heritage reuse process must consider two aspects. First, the regional scale, which provides a suitable method to use environmental resources and implement heritage planning measures, such as accessibility, aesthetics, and safety [18-21]. Second, the local scale, which focuses on cultural and social features and identifies aspects of the cultural environment for site planning, such as landscape type, usability, safety, and aesthetics [18,19,21,22].

Natural landscapes are important in the process of adaptive heritage reuse. In heritage studies, natural landscapes and green spaces shape heritage spaces; evoke tranquillity; and create leisure, social, and cultural activities [23]. The benefits of several heritage sites are derived from the surrounding green space [24], and natural landscapes are often preferred for their scenic and recreational appeal. Several studies have also demonstrated that the natural landscape is the most preferred visual element and produces physiological and psychological benefits [25-27]. For visitors, natural landscapes are important attractions, and adaptive heritage reuse processes must consider the multiple aspects of value and the visitors' need for an attractive destination if economic benefits are to be expected. From the process of destruction to adaptive heritage reuse, the changes in a heritage site's landscape transform the location's value for the original users into a multitude of values-including cultural, social, landscape, and environmental values-for new users [28,29]. For example, the process of adaptive heritage reuse often changes a heritage site into a recreational site and produces recreational value to match visitors' expectations and intrinsic motivations. Landscape and environmental value ensure a harmonious relationship between the visitors and a landscape [28]. The values of landscapes and the environment are vital parts of heritage and have a major effect on inducing attraction, benefits, purchase intention, and brand uniqueness [30]. Therefore, these intangible values that form part of the visitors' experience should not be overlooked.

To sum up, a heritage site's attractiveness involves regional features, landscape features, and multiple values. However, few studies to date have explored the role of recreational attractiveness in 
adaptive heritage reuse processes; also, no theoretical framework exists to understand the attractive features and recreational values of heritage sites that have undergone adaptive heritage reuse processes. Such a framework would favour the establishment of a planning principle based on sustainable management for heritage sites. This study has two aims: (1) exploring attractive features and values as an aspect of adaptive heritage reuse processes from a recreational perspective and (2) searching for the interconnection between multiple features and values and developing a theoretical framework for attractiveness in terms of adaptive heritage reuse processes. Thus, this study will have theoretical and practical implications for the development of adaptive heritage reuse.

\section{Materials and Methods}

\subsection{Research Site}

This study focused on heritage sites that had undergone adaptive heritage reuse. A previous study evaluated the different historical stages of heritage sites that have undergone adaptive heritage reuse in Taiwan through a newspaper content analysis [17]. Based on this research, the current study selected nine cases of adaptive heritage reuse from different historical stages in Taiwan's history, which were evaluated positively. These sites were surveyed to reduce the effect of the particular features of a single type of heritage site. The nine study sites are coded A to I and illustrated in Table 1.

Table 1. Study sites in adaptive heritage reuse.

\begin{tabular}{|c|c|c|c|}
\hline Code & Study Site and Characteristic & $\begin{array}{l}\text { Survey } \\
\text { Date }\end{array}$ & $\begin{array}{l}\text { Number of } \\
\text { Respondents }\end{array}$ \\
\hline A & $\begin{array}{l}\text { Natural Way Six Arts Cultural Centre } \\
\text { Location: Urban area (in Central Taiwan) } \\
\text { Year built: } 1937 \text { (Japanese rule) } \\
\text { Heritage style: Japanese martial arts hall } \\
\text { Environment: Lots of green space } \\
\text { Activity: Creative market }\end{array}$ & 2019/01/06 & 10 \\
\hline B & $\begin{array}{l}\text { Huashan } 1914 \text { Creative Park } \\
\text { Location: Urban area (in North Taiwan) } \\
\text { Year built: } 1916 \text { (Japanese rule) } \\
\text { Heritage style: Japanese winery } \\
\text { Environment: Artistic decoration and atmosphere } \\
\text { Activity: Static and dynamic exhibition }\end{array}$ & 2019/01/12 & 10 \\
\hline $\mathrm{C}$ & $\begin{array}{l}\text { Fortress San Domingo } \\
\text { Location: Sub-urban area (in North Taiwan) } \\
\text { Year built: } 1646 \text { (Dutch and Spanish Formosa) } \\
\text { Heritage style: English- and Chinese-style fort } \\
\text { Environment: Historical decoration with a wide riverscape } \\
\text { Activity: Static exhibition }\end{array}$ & 2019/01/13 & 10 \\
\hline $\mathrm{D}$ & $\begin{array}{l}\text { The British Consulate at Takow } \\
\text { Location: Urban area (in South Taiwan) } \\
\text { Year built: } 1879 \text { (Ming and Qing rule) } \\
\text { Heritage style: English-style consulate } \\
\text { Environment: Historical decoration with mountain } \\
\text { and seascape } \\
\text { Activity: Static exhibition }\end{array}$ & 2019/01/19 & 10 \\
\hline
\end{tabular}


Table 1. Cont.

\begin{tabular}{|c|c|c|c|}
\hline Code & Study Site and Characteristic & $\begin{array}{c}\text { Survey } \\
\text { Date }\end{array}$ & $\begin{array}{l}\text { Number of } \\
\text { Respondents }\end{array}$ \\
\hline $\mathrm{E}$ & $\begin{array}{l}\text { Sinhua Historical Township Office Restaurant } \\
\text { Location: Sub-urban area (in South Taiwan) } \\
\text { Year built: } 1934 \text { (Japanese rule) } \\
\text { Heritage style: Renaissance-style architecture } \\
\text { Environment: Modern street and road } \\
\text { Activity: Restaurant }\end{array}$ & 2019/01/19 & 10 \\
\hline $\mathrm{F}$ & $\begin{array}{l}\text { Haishan Hostel } \\
\text { Location: Sub-urban area (in South Taiwan) } \\
\text { Years built: } 1736 \text { (Ming and Qing rule) } \\
\text { Heritage style: Chinese hall and temple } \\
\text { Environment: Creative and historical decoration } \\
\text { and atmosphere } \\
\text { Activity: Static exhibition }\end{array}$ & $2019 / 01 / 20$ & 10 \\
\hline G & $\begin{array}{l}\text { Kishu An Forest of Literature } \\
\text { Location: Urban area (in North Taiwan) } \\
\text { Years built: } 1917 \text { (Japanese rule) } \\
\text { Heritage style: Japanese building for restaurant } \\
\text { Environment: Mixed new and old building with lots of } \\
\text { green space } \\
\text { Activity: Static exhibition }\end{array}$ & $2019 / 01 / 22$ & 10 \\
\hline $\mathrm{H}$ & $\begin{array}{l}\text { Nishi Honganji Square } \\
\text { Location: Urban area (in North Taiwan) } \\
\text { Years built: } 1922 \text { (Japanese rule) } \\
\text { Heritage style: Japanese temple } \\
\text { Environment: Modern street with green space } \\
\text { Activity: Static exhibition and restaurant }\end{array}$ & $2019 / 01 / 27$ & 10 \\
\hline I & $\begin{array}{l}\text { Songshan Cultural and Creative Park } \\
\text { Location: Urban area (in North Taiwan) } \\
\text { Years built: } 1937 \text { (Japanese rule) } \\
\text { Heritage style: Modernised tobacco factory } \\
\text { Environment: Artistic decoration and atmosphere } \\
\text { Activity: Creative market, static, and dynamic exhibition }\end{array}$ & $\begin{array}{l}2019 / 01 / 23 \\
2019 / 01 / 25\end{array}$ & 10 \\
\hline
\end{tabular}

\subsection{Sample Selection}

The study was approved by the National Cheng Kung University Human Research Ethics Committee (approval number: NCKU HREC-E-107-119-2). Formal interviews were conducted from 6 to 27 January 2019, with visitors who were conveniently sampled from the nine research sites. All study subjects were adult visitors over the age of 20 . A constant comparative analysis with a sampling strategy of theoretical saturation was used to generate a theoretical framework and new categories [31,32]. Theoretical saturation occurs when no additional data can be obtained from new respondents, and sampling is thus stopped [31,33]. At each survey site, 10 respondents were interviewed. In the first wave, interview data were analysed from 50 respondents at sites A to E. When analysing the data from 40 further interviews at sites $\mathrm{F}$ to I through the constant comparative process, no additional information was found. Therefore, this study stopped the sampling process and planned further research sites as theoretical saturation had occurred. A total of 90 visitors were interviewed, including 59 females $(65.6 \%)$ and 31 males (34.4\%). The higher percentage of female participants probably reflected a higher willingness to be interviewed. The interviews were conducted in Chinese, and all respondents were regular Taiwanese users, day visitors, or tourists. 


\subsection{Open-Ended Interviews}

The outline of the open-ended interviews is illustrated in Table 2. The respondents were first asked, "Do you like this site?" followed by the follow-up question, "What features attracted you to this site?" to capture attractive features concerning adaptive heritage reuse. The probe question "Why is this (feature) important to you?" was asked to determine why a particular feature was important to the respondent and understand the visitors' values. The process of asking probe questions was repeated until the respondent's perspective was clear [32,33]. Second, the questions "What features attracted you from home/accommodation to this site?" and "Why is this (feature) important to you?" were used to capture regional features and the visitors' values.

Table 2. Outline of the interviews.

\begin{tabular}{|c|c|c|}
\hline Step & Open-Ended Questions & Purpose of the Questions \\
\hline Step 1 & $\begin{array}{l}\text { Do you like this place? What features attracted } \\
\text { you to this place? }\end{array}$ & Capture attractive features \\
\hline \multirow{3}{*}{ Step 2} & Why is this (feature) important to you? & Understand visitors' values \\
\hline & $\begin{array}{l}\text { What features attracted you from } \\
\text { home/accommodation to this place? }\end{array}$ & Capture regional features \\
\hline & Why is this (feature) important to you? & Understand visitors' values \\
\hline
\end{tabular}

The interviews were conducted by two research assistants with a background in landscape and horticulture. A training workshop was held to explain the research content, interview outline, interview method, and guidelines. Each research assistant conducted practice interviews with five graduate students, and the first author repeatedly checked that the interview process was effective to ensure quality and consistency.

In the first step, the research assistants provided the following information to the study subjects through a consent form: the interview would last approximately $15 \mathrm{~min}$, the interview would be recorded via a digital voice recorder, the researcher would protect and anonymise the interview data, and participants would receive NT \$50 after completing the interview. Once the consent forms had been signed, the interviewer conducted the interview, and the entire interview was recorded to preserve its trustworthiness. The interviews lasted approximately 10-15 min on average, and the research assistants transcribed them verbatim from the interview recorder. The first author repeatedly checked the accuracy of the verbatim content before the data analysis.

\subsection{Data Analysis}

As trustworthiness is a critical quality in qualitative research [31,34], this study describes in detail the study strategies used for the method, process, results, and discussion. A constant comparative analysis was utilised to analyse the data on heritage sites' attractive features and visitors' values and to build a theoretical framework from the interview transcripts. The data analysis was divided into four stages based on the methods developed by Glaser and Strauss [31], Patton [32], and Ritchie et al. [33]. First, each meaningful paragraph of interview data regarding attractive features and values about adaptive heritage reuse was coded into categories of analysis. To ensure the coding reliability, three researchers (the study author and two independent researchers with master's degrees in landscape design) conducted the open coding separately and established the preliminary categories through constant comparison and negotiation.

Second, the preliminary categories were integrated based on the properties of the category after the completion of the open coding of each transcript. The three researchers worked independently to determine the common concepts and then recombined similar code terms and categories to include all the identified concepts. The diverse properties of categories also began to be integrated, and the initial theoretical framework was developed through constant comparisons. A debriefing session was held 
with the three researchers to explain the developing ideas, interpretations, and feedback and to reduce the effect of analyst bias.

Third, the researchers developed a second-level classification system to identify all the categories and concepts necessary to delimit the theory. There were two major theoretical requirements: (1) simplicity of categories and concepts and (2) the theory should match the data analysis and apply to a wide range of situations [31]. This study constructed a theoretical framework with three levels of attractiveness for adaptive heritage reuse from local to regional scales: reuse environment, natural environment, and regional environment (Table 3). The heritage site and activity consisted of two clear and non-overlapping themes in the heritage reuse environment, and the visitors' values were captured from the attractive features of the heritage sites through the probe questions. The four themes for the recreational values of heritage were self-growth, health benefit, social benefit, and cultural benefit (Table 4). Inter-coder reliability was assessed using Krippendorff's alpha to ensure that the process of code was correct and consistent [35-37]. Krippendorff's alpha was 0.88 , indicating good reliability in the process of code.

Table 3. Themes and subthemes emerged from the open-ended questions.

\begin{tabular}{lllc}
\hline Scale & Theme & Subtheme & Times \\
\hline Local scale & A1 Reuse environment: Heritage & Heritage architecture & 52 \\
& & Cultural atmosphere & 49 \\
& & Heritage style & 24 \\
& & Well-preserved heritage & 23 \\
& A2 Reuse environment: Activity & History and culture & 13 \\
& & Feritage decoration & 11 \\
& & Static art activities & 38 \\
& & Walking & 34 \\
& & Family activities & 13 \\
& & Dynamic art activities & 10 \\
& & Leisure atmosphere & 7 \\
& & Natural landscape & 61 \\
& & Wide landscape & 44 \\
& & Well-maintained environment & 23 \\
& & Safe environment & 21 \\
& & Surrounding tourist attraction & 3 \\
& & High transportation accessibility & 25 \\
& & Historical street & 22 \\
\hline
\end{tabular}

Table 4. Themes and subthemes of benefits of heritage from open-ended interviews.

\begin{tabular}{llc}
\hline Theme & Subtheme & Times \\
\hline V1 Self-growth & Learning & 53 \\
& Growth & 25 \\
& Rethinking & 18 \\
& Work motivation & 11 \\
& Achievement & 3 \\
V2 Health benefit & Positive emotion & 121 \\
& Coping & 80 \\
& Good life & 6 \\
V3 Social benefit & Health maintenance & 4 \\
& Relationship promotion & 33 \\
V4 Cultural benefit & Memories & 17 \\
& Cultural inheritance & 3 \\
& A sense of belonging & 3 \\
\hline
\end{tabular}


This study attempted to analyse the relationship between attractive features and recreational values concerning adaptive heritage reuse to develop a theoretical framework. In the final stage, the constant comparison of coded data and theoretical framework was used to develop a new theory. A review of previous research was conducted to assess the overall rationality of the theoretical framework [34], as shown in the discussion section.

\section{Results}

\subsection{Attractive Features for Adaptive Heritage Reuse}

\subsubsection{Reuse Environment: Heritage}

In the reuse environment, heritage plays an important role in the recreational attractiveness resulting from the process of adaptive heritage reuse. The heritage theme has six subthemes: heritage architecture, cultural atmosphere, heritage style, well-preserved heritage, history and culture, and heritage decoration. Heritage architecture, heritage style, and heritage decoration constitute the physical aspects of the heritage buildings. Heritage architecture refers to a positive description of the heritage building itself; for example, "I like old buildings" (J07). Heritage style refers to instances where respondents indicated the specific historical style of the building. Japanese-style was often mentioned, including aspects such as Japanese buildings, clock tower, gallery, and room; for example, "I like Japanese-style architecture very much, especially wooden houses" (F08). Heritage decoration refers to the architectural decoration that attracted the respondents to the site, including features such as relics, artefacts, floors, walls, brick, paving, materials, and sculptures; for example, "There will be some fixed decorations in historical monuments" (D10).

Several attractive features were presented through abstract descriptions of the heritage buildings, including the cultural atmosphere, well-preserved heritage, and history and culture. Cultural atmosphere means that the heritage building feels ancient, nostalgic, simple, or unsophisticated; for example, "I feel that there is a feeling of historical features" (I10). Well-preserved heritage means that the heritage building was well-preserved or that old and new cultural elements were well combined in the process of adaptive heritage reuse; for example, "I like that the heritage site retains the original building structure and materials" (G04). The category history and culture was applied when respondents indicated that the building had historical and cultural significance; for example, "I think old castles have historical and cultural characteristics" (G02).

\subsubsection{Reuse Environment: Activity}

The activity theme refers to activities developed through the adaptive heritage reuse process to attract visitors, including food enjoyment, static art activities, dynamic art activities, walking, and family activities. Activities were found to be an important reuse form to construct recreational attractiveness, and activity planning played an important role in the successful adaptive heritage reuse process. The adaptive heritage reuse processes can provide opportunities for visitors to undertake activities, and this adds to the attractiveness of a location/destination, making it a relevant factor in planning any adaptive heritage reuse projects. Food enjoyment was identified as the goal of some visitors, who planned to enjoy meals, snacks, and afternoon tea in the heritage site stores; for example, "I come here to have afternoon tea. I feel I can release pressure for my heart" (J04).

Static art activities emerged as an important activity too, as some visitors wanted to see exhibitions, creative activities, creative markets, lectures, and movies in the heritage sites' indoor and outdoor spaces; for example, "I often come here to see the exhibitions" (A03). Some visitors came to attend dynamic art activities, such as performances by musicians and street artists or enjoy activity experiences (e.g., Kendo); for example, "Some street artists' performances are also wonderful" (I07). Walking means that the heritage site environment is suitable for walking; for example, "It is very suitable for 
everyone to take a walk here" (J05). Family activities refers to the heritage site's suitability for playing with children or family members; for example, "I can bring the children to play here" (D09).

\subsubsection{Natural Environment}

The respondents often mentioned the attractiveness of the outdoor environment apart from the reused heritage, and the physical landscape and abstract atmosphere of the natural environment created recreational attractiveness. The theme of the natural environment has five subthemes: leisure atmosphere, natural landscape, wide landscape, well-maintained environment, and safe environment. Natural landscape refers to a merely physical description of the heritage site's outdoor environment, including sky, sun, daylight, air, shade, plants, trees, bamboo forest, turf, stone, wood path, ecological pool, river, harbour landscape, park, garden, and green space; for example, "The natural landscape with rivers and some old trees is quite special around the heritage site" (A03) and "I feel some places are quite natural, such as the wood path, stone, etc. ... Trees with shade are good" (B02).

The leisure atmosphere, wide landscape, well-maintained environment, and safe environment comprised abstract descriptions of the heritage site's outdoor natural environment. Leisure atmosphere describes the feeling of tranquillity and liveliness, while also referring to the leisure and artistic nature of the heritage site's outdoor environment; for example, "It should be said that the life tempo is quite slow here. You can be very leisurely" (I04). The content of the wide landscape comprises descriptions of visual and landscape openness; for example, "It is relatively visually wide here" (F03). Well-maintained environment means that the indoor and outdoor environments are clean and tidy; for example, "Here is different. The environment is neat and tidy due to management. The environment is elegant" (E03). Finally, some respondents indicated that safety is also considered in evaluating the heritage site's outdoor environment; for example, "I can bring my children to a safer space when I have tea and chat here" (E05). Child safety and facility safety were also attractive features of heritage sites' environments.

\subsubsection{Regional Environment}

The theme regional environment was related to the recreational attractiveness of large-scale features and indicated that surrounding tourist attractions, high transportation accessibility, and historical streets attract to the heritage site destination. The surrounding tourist attractions and historical streets comprised physical descriptions of regional and geographical features. Historical streets included landscape and decorations of streets, lanes, and alleys; for example, "The western-style streetscape or decoration brings a sense of novelty that attracts people to stay here. I think it is a big attraction" (D07).

Surrounding tourist attractions included non-cultural heritage in the region, such as restaurants, business districts, trails, and markets; for example, "We just came from the Taichung Second Market. It is the traditional market. I have not visited a traditional market for a long time. It is quite special" (B06). High transportation accessibility was only an abstract description of regional and geographical features and it refers to the availability of transportation and parking spaces; for example, "I feel that the transportation is convenient and comfortable" (F08). Therefore, to promote recreational attractiveness, the process of adaptive heritage reuse should consider not only the reuse environment but also the natural environment and local and regional environments.

\subsection{The Values of Attractive Features of Adaptive Heritage Reuse}

\subsubsection{Recreational Value of Adaptive Heritage Reuse}

Learning, growth, rethinking, work motivation, and achievement were generalised as self-growth. Learning refers to the positive experience of heritage; for example, "I have begun to recognise living space and characteristics through this opportunity" (D10). Growth means that the heritage experience induces self-growth, including knowledge, skills, and new experiences; for example, "I feel that I know more about historical concepts" (D08). Rethinking means that the heritage experience induces 
reconsideration or different ideas about life or work; for example, "I feel I can change my perspectives about other things" (A04). Work motivation means that the heritage experience allows respondents to recover work motivation through relaxation; for example, "The experience is just like an energy supplement when I return to the company" (G04). Achievement means that the heritage experience produces satisfaction; for example, "It is very satisfying. Healing my spirit" (I09).

The subthemes of positive emotions, coping, good life, and health maintenance were generalised into health benefits. Positive emotion means that the heritage experience promotes happiness, gladness, delight, pleasure, ease, comfort, freshness, and excitement; for example, "I feel ease and pleasure here" (D01). Coping means that the heritage experience releases the pressure of urban life; for example, "Because my work is stressful and urgent, I occasionally go to relax" (D02). Good life means that the heritage experience positively affects long-term life values; for example, "The whole life may be more colourful" (E09). Health maintenance means that the heritage experience fosters physical and mental health; for example, "A feeling of health. It slows down ageing" (E03).

Relationship promotion and memories were generalised as social benefits. Relationship promotion means that the heritage experience promotes social interactions with family and friends; for example, "When I get home, I will tell my family about my experience. My family will be excited and will want to come here if they are interested" (G04). Memories means that the heritage experience and taking photos with family and friends become valuable memories; for example, "I will keep these memories because it has the characteristics of Taiwan" (D05).

Some people mentioned the cultural benefit of heritage experience. Cultural inheritance and a sense of belonging were generalised into cultural benefits. Cultural inheritance means that the heritage experience promotes cultural transmission between generations; for example, "When he grows up, he can bring the next generation to talk about history here. It seems to be an inheritance" (E05). A sense of belonging means that the heritage experience promotes recognition and pride in one's culture; for example, "Of course, I feel happy to see heritage changes because this is also a local characteristic" (E01).

\subsubsection{The Relationship between Attractive Features and Recreational Values}

This study established the interconnection between four attractive features and four recreational values of heritage (Figure 1). Sixty-six interviewees indicated that heritage features produce health benefits; for example, "The entire open space, natural light, and gallery are the characteristics of architecture. We can stay inside without a time limit. So, I feel quite relaxed" (A03). Forty-four interviewees indicated that the heritage features induce self-growth; for example, "It is great to be able to regenerate ancient architecture. ... It is quite good for the government to give this ancient architecture a new life ... In this fast-paced world, it shows me the original value of life and [that we have] not lost our direction. There is no way to enjoy the many processes of life if you have not settled down" (B04). Eighteen interviewees indicated that heritage features produce social benefits; for example, "Although the architecture is older on this site, I think the architecture has retained its characteristics.... I may tell my friends about this place. If they have the opportunity to come here, I will introduce this place to them" (D05).

The activity was also an important feature in terms of self-growth, health, and social benefits. Forty-five interviewees indicated that the activity feature produces health benefits; for example, "This place holds some irregular exhibitions. It makes me feel more relaxed in the city" (I04). Thirty interviewees indicated that the activity feature produces growth; for example, "Sometimes, there are small exhibitions. It is suitable to experience with children here ... I like scientific exhibitions there. It allows children to see something new. He asked why the ball floats" (I06). Sixteen interviewees indicated that the activity feature produces social benefits; for example, "The whole space is huge. The contents of several exhibitions are quite interesting ... I come here with friends if I want to go shopping or if there is an exhibition that I am interested in" (J08). 


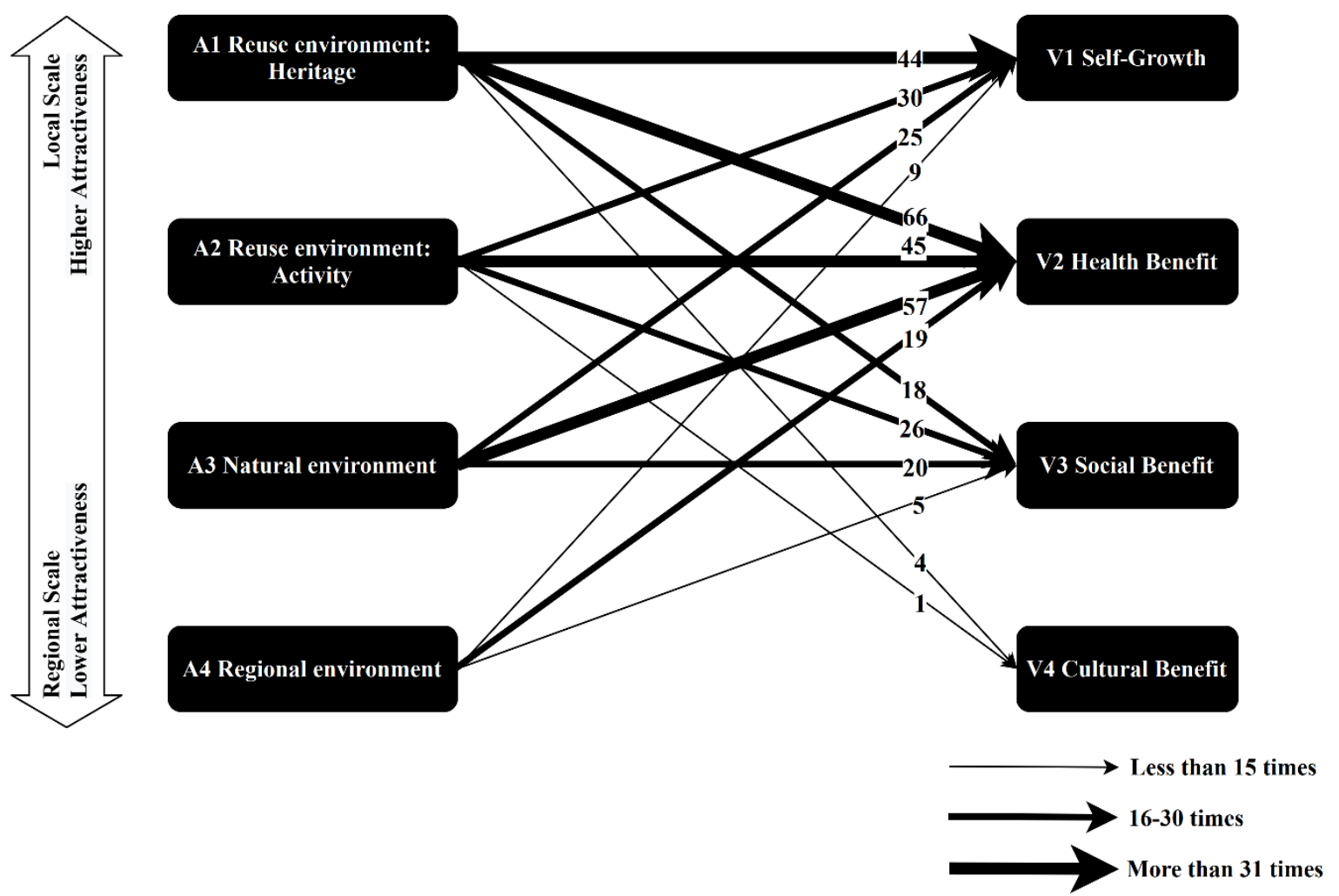

Figure 1. The relationship between attractive features and recreational values.

The natural environment was a critical feature in terms of self-growth, health benefits, and social benefits. Fifty-seven interviewees indicated that nature and the outdoor landscape produce health benefits; for example, "Outdoors. The whole landscape looks great. The whole sunbathing in the sunshine makes me feel very healthy" (F08). Twenty interviewees indicated that the natural environment produces self-growth; for example, "Lots of green plants.... Relaxation ... I will work actively" (I01). Twenty-five interviewees indicated that the natural environment produces social benefits; for example, "Actually, I come here in different seasons. I observe the difference between each season, such as the fallen leaves and cloudy days ... It is good to take photos at some angles where the sun is shining ... At this time, I will recommend friends to come here... I can communicate with friends" (D01).

Although the connection between the reuse environment and value was mentioned more often, the feature of the regional environment also contributes to self-growth, health, and social benefits; for example, "I passed a part of the old street. ... I am gradually getting to know the environments and characteristics of my community through this opportunity. Later, I will take my friends to special spaces here" (D10), and "There is a special favourite bar-restaurant here. ... I will come here to have a drink with my friends. ... Relax and relieve stress. Then, chat with friends or talk about recent troubles. Drink and relieve stress" (I10). Furthermore, five interviewees mentioned the relationship between the reuse environment and cultural benefits. Comparatively, few features contribute to cultural benefits; for example, "I like that the structure and materials of the original architecture were retained ... I think that this is cultural preservation ... I also teach my child. This is our cultural inheritance" (G04). In this study, the reuse environment, natural environment, and regional environment produced self-growth, health benefits, and social benefits. Only cultural benefits were induced by the heritage and activity features of the reuse environment. 


\section{Discussion}

\subsection{Theoretical Framework}

This study is the first to examine the adaptive heritage reuse process from a recreational perspective focusing on sites' attractiveness. The results of the qualitative interviews with the visitors demonstrate that the heritage and activities of a reuse environment, natural environment, and regional environment are critical for recreational attractiveness. This study also attempted to connect the attractive features of the heritage sites and the values of the visitors. Although only the heritage and activity of the reuse environment produced cultural benefits, the results confirmed that the four attractive features produced three recreational values: self-growth, health benefits, and social benefits. Therefore, this study constructed a theoretical framework of attractiveness for adaptive heritage reuse based on the recreational values of heritage and activity of the reuse environment, natural environment, and regional environment.

\subsection{Theoretical Support for the Framework: Reuse Environment}

Architectural heritage resources are the most attractive to visitors [38], and several studies focused on how to rank heritage building conversion through experts' decision-making with multiple criteria [39,40]. This study indicated that heritage architecture, decoration, and style attracted visitors, though history and culture, cultural atmosphere, and well-preserved heritage were also important attractors. Heritage also induced self-growth, health, and social and cultural benefits. Similarly, previous studies indicated that building materials and techniques might inspire visitors to learn about the particular culture of the local community [10].

Recreation programming is an important factor in designing leisure experiences and attracting visitors from the perspective of leisure and recreation [41]. Heritage sites are often visualised as places of leisure and markets because such places can hold social activities that help to create a cultural identity [23]; for example, community activities were important in the process of museum reuse [42]. A further contribution of this study is to demonstrate that activity is an important attractor, including food enjoyment, static art activities, dynamic art activities, walking, and family activities; for example, the heritage visitors often had a greater interest in the local gastronomy [10,11]. Although the above activities were not tied to the heritage sites' original function and cultural purpose, this study indicated an important link between heritage and recreational values, including self-growth, health, and social interaction. Adaptive heritage reuse processes do not only entail cultural protection, but they also create recreational opportunities.

\subsection{Theoretical Support for the Framework: Natural Environment}

The outdoor space between heritage architecture and the street has been defined as an outdoor living room that affects recreational behaviour [43]. The heritage site's outdoor environment plays a large role in the overall experience, bolstering the heritage site's attractiveness, encouraging visitors to share the experience with friends and family, and ensuring the continuity of the brand's meaning and uniqueness [30]. For example, rivers act as a boundary and location of heritage sites that reflect the history, link memories, induce place meaning, and create local history [23].

In this study, the natural environment was an important outdoor attractor that created health benefits, social benefits, and self-growth. Several studies have demonstrated that nature has a therapeutic effect of relieving fatigue and the pressures of urban life and promoting landscape preference, based on attention restoration and landscape preference theory [26]. In recreational studies, grass, shrubs, trees, gardens, water, natural sounds, clean air, and special aromas have been found to promote recreational attractiveness [44]. In this study, plants, rivers, parks, gardens, and green spaces were seen as suitable natural elements to decorate heritage sites' outdoor environments.

The activity function is also closely associated with the natural environment. The natural landscape and green space often create tranquillity, leisure opportunities, and social activities that shape cultural 
spaces, such as rivers, green spaces, and parks [23]. As such, many heritage sites' values come from the surrounding green space [24]. In this study, Japanese-style heritage was the favourite style of architecture and decoration and included natural plants and decorations with natural elements after adaptive reuse. The natural landscape was seen as a positive environment for restoration [25-27] and is, therefore, an important factor in adaptive heritage reuse processes due to the activity function. Consequently, the natural environment can be considered an advantageous factor when selecting heritage sites for preservation.

\subsection{Theoretical Support for the Framework: Regional Environment}

From the viewpoint of recreational behaviour theory, the regional environment likely affects travel experience; for example, the regional environment of the urban park probably affects recreational attractions and behaviours, such as street trees and landscape aesthetics on the roads [45-48]; the regional environment becomes part of the recreation experience [49]. In this study, historical streets and surrounding tourist attractions were the two physical features that contributed to a heritage site's attraction, and the landscape, atmosphere, and decorations of the historical street were important tourist attractions. Some non-cultural places also served as attractions in the regional environment, such as restaurants, business districts, trails, and markets. Regional historical streets and tourist spots can be important in determining what heritage to preserve in the process of adaptive heritage reuse. Regional streets should be consistent with the historical characteristics of the heritage site's landscape.

In previous studies, road networks, population density, and urbanisation have been found to have a high value in terms of a heritage site's accessibility, location, and potential benefits [50]. Accessibility is an important factor in determining the choice of destination [51,52], and visitors often consider transportation accessibility during the decision-making process [51]. The higher the accessibility, the higher the frequency of participation and benefits, particularly for users of parks, courts, and restaurants [53,54].

In this study, convenient transportation and well-planned parking spaces were the two main aspects affecting the accessibility to heritage sites. Limited transportation accessibility probably indirectly reduces visitors' willingness to visit the sites unless the destination has a unique irreplaceability [51]. A heritage site's transportation accessibility can also be used to assess its attractiveness in the process of adaptive heritage reuse, and transportation accessibility can be considered a relevant regional factor in prioritising the preservation of some sites from a recreational perspective.

\subsection{Recreational Benefit as a Major Factor in Adaptive Heritage Reuse}

Adaptive heritage reuse delivers benefits that contribute to fulfilling visitor motivations for visiting a destination. Self-growth, health benefits, social benefits, and cultural benefits were four important aspects of adaptive heritage reuse. Health benefits included positive emotions, coping, a good life, and health maintenance. Several visitors obtained self-growth by visiting heritage sites, including learning, growth, rethinking, work motivation, and achievement. Others promoted social relationships, including forming memories and social interactions with family and friends. Cultural benefits included cultural inheritance and a sense of belonging. Interestingly, few cultural benefits were mentioned in this study, for two reasons. First, it may be difficult for short-term heritage tourism to form long-term cultural values. Most respondents in this study acquired historical knowledge only for self-growth and were not interested in understanding cultural inheritance and feeling a sense of belonging. Second, visitors' major motivations may be health benefits, social benefits, and self-growth, which are intrinsic motivations. The adaptive heritage reuse process is not only applied to cultural heritage but also public leisure and recreational spaces.

\subsection{Practical Implications and Future Research}

In terms of practical implications, the theoretical framework developed in this paper can inform the planning of adaptive heritage reuse and determine the priorities to achieve sustainable management of 
urban heritage. First, the availability of activities to attract people to a destination should be considered when planning/deciding to undertake adaptive heritage reuse of a site or location. Both cultural and non-cultural activities foster self-growth, health benefits, and social benefits. Sustainable adaptive heritage reuse management should emphasise activity planning to create multiple values of heritage, attract visitors and private funds, and simultaneously reduce the financial burden.

Second, the natural environment and landscape should be used in the design of heritage sites' outdoor environments. The natural environment not only adds beauty to the heritage site but also has an activity function and recreational values. Finally, the potential natural and regional environment can be an important basis for assessing suitable heritage sites, and high transportation accessibility, the surrounding tourist attractions, and historical streets were the three main factors for assessing adaptive heritage reuse feasibility.

This study did not apply quantitative methods to provide evidence for the theoretical framework. Future research should use exploratory factor analysis and confirmatory factor analysis to provide evidence for the theoretical framework through a quantitative survey. Additionally, only three respondents indicated that the reuse environment produced cultural benefits. Although this study attempted to connect heritage and values, the qualitative interviews produced no clear conclusion on this issue. Future research should examine the relationship between adaptive heritage reuse attractiveness and values through a quantitative survey, particularly for cultural benefits.

\section{Conclusions}

This study explored destinations' attractiveness from a recreational perspective to develop a theoretical framework for heritage planning principles. The study results generalise adaptive heritage reuse as the reuse environment, natural environment, and regional environment that are connected with recreational values, including self-growth, health benefits, and social benefits. This theoretical framework can be used as a planning principle to achieve the sustainable management of urban heritage, especially for government administrators. Although the attractiveness of a heritage site's architecture is an important feature of adaptive heritage reuse, activities are also a critical attractor for visitors. Activity planning should be considered to satisfy visitors' needs and promote a heritage destination's attractiveness. The natural landscape should also be considered as an important factor in matching visitors' needs and values. Finally, regional features and visitors' needs should be important bases for assessing adaptive heritage reuse feasibility and ensuring sustainable development.

Funding: The author disclosed receipt of the following financial support for the research, authorship, and/or publication of this article: This work was supported by the Ministry of Science and Technology (MOST) [Project No. MOST 107-2410-H-005-028-MY3].

Acknowledgments: The author is sincerely grateful to the Ministry of Science and Technology (MOST) in Taiwan for its full support (Project No. MOST 107-2410-H-005-028-MY3).

Conflicts of Interest: The author declares no competing interests.

Ethical Review: The study was approved by National Cheng Kung University Human Research Ethics (approval number: NCKU HREC-E-107-119-2).

\section{References}

1. World Heritage. Available online: https://whc.unesco.org/en/about/ (accessed on 12 August 2018).

2. Bullen, P.A. Adaptive reuse and sustainability of commercial buildings. Facilities 2007, 25, 20-31. [CrossRef]

3. Shehata, W.T.A.; Moustafa, Y.; Sherif, L.; Botros, A. Towards the comprehensive and systematic assessment of the adaptive reuse of Islamic architectural heritage in Cairo: A conceptual framework. J. Cult. Herit. Manag. Sustain. Dev. 2015, 5, 14-29. [CrossRef]

4. Bullen, P.A.; Love, P.E. Adaptive reuse of heritage buildings. Struct. Surv. 2011, 29, 411-421. [CrossRef]

5. Plevoets, B.; Van Cleempoel, K. Adaptive reuse as a strategy towards conservation of cultural heritage: A literature review. In Structural Studies, Repairs, and Maintenance of Heritage Architecture XII; Brebbia, C., Binda, L., Eds.; WITpress: Chianciano Terme, Italy, 2011; pp. 155-163. 
6. Elsorady, D.A. Assessment of the compatibility of new uses for heritage buildings: The example of Alexandria National Museum, Alexandria, Egypt. J. Cult. Herit. 2014, 15, 511-521. [CrossRef]

7. Pendlebury, J.; Wang, Y.W.; Law, A. Re-using 'uncomfortable heritage': The case of the 1933 building, Shanghai. Int. J. Herit. Stud. 2018, 24, 211-229. [CrossRef]

8. Bedate, A.; Herrero, L.C.; Sanz, J.Á. Economic valuation of the cultural heritage: Application to four case studies in Spain. J. Cult. Herit. 2004, 5, 101-111. [CrossRef]

9. Pedersen, A. Managing Tourism at World Heritage Sites: A Practical Manual for World Heritage Site Managers; UNESCO World Heritage Centre: Paris, France, 2002.

10. Leanza, P.; Porto, S.; Sapienza, V.; Cascone, S. A heritage interpretation-based itinerary to enhance tourist use of traditional rural buildings. Sustainability 2016, 8, 47. [CrossRef]

11. Porto, S.M.; Leanza, P.M.; Cascone, G. Developing interpretation plans to promote traditional rural buildings as built heritage attractions. Int. J. Tour. Res. 2012, 14, 421-436. [CrossRef]

12. Yıldırım, M.; Turan, G. Sustainable development in historic areas: Adaptive re-use challenges in traditional houses in Sanliurfa, Turkey. Habitat Int. 2012, 36, 493-503. [CrossRef]

13. Yung, E.H.; Chan, E.H.; Xu, Y. Community-initiated adaptive reuse of historic buildings and sustainable development in the inner city of Shanghai. J. Urban Plan. Dev. 2013, 140, 05014003. [CrossRef]

14. Yung, E.H.; Chan, E.H. Implementation challenges to the adaptive reuse of heritage buildings: Towards the goals of sustainable, low carbon cities. Habitat Int. 2012, 36, 352-361. [CrossRef]

15. Hu, Y.; Ritchie, J.B. Measuring destination attractiveness: A contextual approach. J. Travel Res. 1993, 32, 25-34.

16. Yung, E.H.; Langston, C.; Chan, E.H. Adaptive reuse of traditional Chinese shophouses in government-led urban renewal projects in Hong Kong. Cities 2014, 39, 87-98. [CrossRef]

17. Chen, H.M.; Tu, H.M. Adaptive reuse and implementation challenges to contracting out urban declared monument and historic buildings in Taiwan. In Inheriting the City: Advancing Understandings of Urban Heritage; Ironbridge International Institute for Cultural Heritage: Taipei, Taiwan, 2016.

18. Bedimo-Rung, A.L.; Mowen, A.J.; Cohen, D.A. The significance of parks to physical activity and public health: A conceptual model. Am. J. Prev. Med. 2005, 28, 159-168. [CrossRef] [PubMed]

19. Fry, G.L.; Skar, B.; Jerpåsen, G.; Bakkestuen, V.; Erikstad, L. Locating archaeological sites in the landscape: A hierarchical approach based on landscape indicators. Landsc. Urban Plan. 2004, 67, 97-107. [CrossRef]

20. Malek, N.A.; Mariapan, M.; Shariff, M.K.M. The making of a quality neighbourhood park: A path model approach. Procedia Soc. Behav. Sci. 2012, 49, 202-214. [CrossRef]

21. Robrahn-González, E.M. Integrating communities from the perspective of continuous archaeology: A case study of Rio de Janeiro, Brazil. In People and Communities, Proceedings of the II Internacional Conference on Best Practices in World Heritage, Madrid, ES, 29 April 2015; Mena, C.A., Ed.; Universidad Complutense de Madrid, Servicio de Publicaciones: Madrid, Spain, 2015.

22. Lin, I.H.; Wu, C.; Sousa, C.D. Examining the economic impact of park facilities on neighboring residential property values. Appl. Geogr. 2013, 45, 322-331. [CrossRef]

23. Lai, L.Y.; Said, I.; Kubota, A. The roles of cultural spaces in Malaysia's historic towns: The case of Kuala Dungun and Taiping. Procedia Soc. Behav. Sci. 2013, 85, 602-625. [CrossRef]

24. Pietrzyk-Kaszyńska, A.; Czepkiewicz, M.; Kronenberg, J. Eliciting non-monetary values of formal and informal urban green spaces using public participation GIS. Landsc. Urban Plan. 2017, 160, 85-95. [CrossRef]

25. Ulrich, R.S.; Simons, R.F.; Losito, B.D.; Fiorito, E.; Miles, M.A.; Zelson, M. Stress recovery during exposure to natural and urban environments. J. Environ. Psychol. 1991, 11, 201-230. [CrossRef]

26. Kaplan, R.; Kaplan, S. The Experience of Nature: A Psychological Perspective; Cambridge University: New York, NY, USA, 1989.

27. Parsons, R. The potential influences of environmental perception on human health. J. Environ. Psychol. 1991, 11, 1-23. [CrossRef]

28. Guidelines for Building Assessment, Preservation, and Utilization. Available online: https://www.aij.or.jp/ scripts/request/document/070810-1.pdf (accessed on 12 October 2017).

29. Stubbs, M. Heritage-sustainability: Developing a methodology for the sustainable appraisal of the historic environment. Plan. Pract. Res. 2004, 19, 285-305. [CrossRef]

30. Bonn, M.A.; Joseph-Mathews, S.M.; Dai, M.; Hayes, S.; Cave, J. Heritage/cultural attraction atmospherics: Creating the right environment for the heritage/cultural visitor. J. Travel Res. 2007, 45, 345-354. [CrossRef] 
31. Glaser, B.G.; Strauss, A.L. Discovery of Grounded Theory: Strategies for Qualitative Research; Routledge: New York, NY, USA, 2017.

32. Patton, M. Qualitative Research and Evaluation Methods; Sage: Thousand Oaks, CA, USA, 2002.

33. Ritchie, J.; Lewis, J.; Nicholls, C.; Ormston, R. Qualitative Research Practice: A Guide for Social Science Students and Researchers; Sage: London, UK, 2013.

34. Shenton, A.K. Strategies for ensuring trustworthiness in qualitative research projects. Educ. Inform. 2004, 22, 63-75. [CrossRef]

35. Lombard, M.; Snyder-Duch, J.; Bracken, C.C. Content analysis in mass communication: Assessment and reporting of intercoder reliability. Hum. Commun. Res. 2002, 28, 587-604. [CrossRef]

36. Hayes, A.F.; Krippendorff, K. Answering the call for a standard reliability measure for coding data. Commun. Methods Meas. 2007, 1, 77-89. [CrossRef]

37. Krippendorff, K. Content Analysis: An Introduction to Its Methodology; Sage: Thousand Oaks, CA, USA, 2004.

38. Gholitabar, S.; Alipour, H.; Costa, C. An empirical investigation of architectural heritage management implications for tourism: The case of Portugal. Sustainability 2018, 10, 93. [CrossRef]

39. Pavlovskis, M.; Migilinskas, D.; Antucheviciene, J.; Kutut, V. Ranking of Heritage Building Conversion Alternatives by Applying BIM and MCDM: A Case of Sapieha Palace in Vilnius. Symmetry 2019, 11, 973. [CrossRef]

40. Šiožinytė, E.; Antuchevičienè, J.; Kutut, V. Upgrading the old vernacular building to contemporary norms: Multiple criteria approach. J. Civ. Eng. Manag. 2014, 20, 291-298. [CrossRef]

41. Rossman, J.R.; Schlatter, B.E. Recreation Programming: Designing Leisure Experiences; Sagamore Publishing LLC: Urbana, IL, USA, 2008.

42. Chen, C.S.; Chiu, Y.H.; Tsai, L. Evaluating the adaptive reuse of historic buildings through multicriteria decision-making. Habitat Int. 2018, 81, 12-23. [CrossRef]

43. Samadi, Z.; Omar, D.; Yunus, R.M. On-street visual analysis on the outdoor space of Jalan Hang Jebat, Melaka. Procedia Soc. Behav. Sci. 2012, 68, 353-362. [CrossRef]

44. McCormack, G.R.; Rock, M.; Toohey, A.M.; Hignell, D. Characteristics of urban parks associated with park use and physical activity: A review of qualitative research. Health Place 2010, 16, 712-726. [CrossRef] [PubMed]

45. Wilcox, S.; Castro, C.; King, A.C.; Housemann, R.; Brownson, R.C. Determinants of leisure-time physical activity in rural compared with urban older and ethnically diverse women in the United States. J. Epidemiol. Community Health 2000, 54, 667-672. [CrossRef] [PubMed]

46. Alves, S.; Aspinall, P.A.; Thompson, C.W.; Sugiyama, T.; Brice, R.; Vickers, A. Preferences of older people for environmental attributes of local parks. Facilities 2008, 26, 433-453. [CrossRef]

47. Kaczynski, A.T.; Potwarka, L.R.; Saelens, B.E. Association of park size, distance, and features with physical activity in neighborhood parks. Am. J. Public Health 2008, 98, 1451-1456. [CrossRef] [PubMed]

48. Sugiyama, T.; Thompson, C.W.; Alves, S. Associations between neighborhood open space attributes and quality of life for older people in Britain. Environ. Behav. 2009, 41, 3-21. [CrossRef]

49. Walsh, R.G.; Sanders, L.D.; McKean, J.R. The consumptive value of travel time on recreation trips. J. Travel Res. 1990, 29, 17-24. [CrossRef]

50. Wright, W.C.; Eppink, F.V. Drivers of heritage value: A meta-analysis of monetary valuation studies of cultural heritage. Ecol. Econ. 2016, 130, 277-284. [CrossRef]

51. Celata, F. Geographic marginality, transport accessibility, and tourism development. In Global Tourism and Regional Competitiveness; Celant, A., Ed.; Patron: Bologna, Italy, 2007; pp. 37-46.

52. Wendel, H.E.W.; Zarger, R.K.; Mihelcic, J.R. Accessibility and usability: Greenspace preferences, perceptions, and barriers in a rapidly urbanizing city in Latin America. Landsc. Urban Plan. 2012, 107, 272-282. [CrossRef]

53. Nielsen, T.S.; Hansen, K.B. Do green areas affect health? Results from a Danish survey on the use of green areas and health indicators. Health Place 2007, 13, 839-850. [CrossRef]

54. Stodolska, M.; Shinew, K.J.; Li, M.Z. Recreation participation patterns and physical activity among Latino visitors to three urban outdoor recreation environments. J. Park Recreat. Adm. 2010, 28, 36-56. 